\title{
Effects of habitat deterioration on the population genetics and conservation of the jaguar
}

S. Roques* ${ }^{1}$, R. Sollman ${ }^{2}$, A. Jacomo ${ }^{2}$, N Torres ${ }^{2,6}$, L. Silveira ${ }^{2}$, C. Chavez ${ }^{3}$, C. Keller ${ }^{4}$, D. Mello do Prado ${ }^{4}$, P. Carignano Torres ${ }^{4}$, C. Jorge dos Santos ${ }^{4}$, X. Bernardes Garcia da Luz ${ }^{4}$, W. E. Magnusson ${ }^{4}$, José A. Godoy $^{7}$, Gerardo Ceballos ${ }^{5}$ and F. Palomares ${ }^{1}$

${ }^{1}$ Department of Conservation Biology, Estación Biológica de Doñana (EBD-CSIC). Avda. Américo Vespucio s/n. 41092, Sevilla, Spain

2 Jaguar Conservation Fund/Instituto Onça-Pintada, C.P. 193, 75830-000 Mineiros - GO, Brazil

3 Departamento de Ciencias Ambientales, División de Ciencias Biológicas y de la Salud, Universidad Autónoma Metropolitana-Unidad Lerma, av. Hidalgo poniente 46, col. La estación, Lerma de Villada, Estado de México, 52006, México.

${ }^{4}$ Instituto Nacional de Pesquisas da Amazônia - INPA, CP 2223, 69080-971 Manaus, Amazonas, Brazil

${ }^{5}$ Instituto de Ecología, Universidad Nacional Autonoma de Mexcio, AP 70-275, México, D.F. 04510, México

${ }^{6}$ Biology Institution, Federal University of Uberlândia - UFU, Campus Umuarama Rua Ceará, s/n, Bloco 2D, 38400-902 Uberlândia-MG, Brazil

7 Department of Integrative Ecology, Estación Biológica de Doñana, Consejo Superior de Investigaciones Científicas

*Correspondence: Séverine Roques. Tel. +34 954466700; fax: +34 954621125. E-mail address: severineroques@hotmail.com

Short title: Jaguar genetic population structure and conservation 


\section{ABSTRACT}

2

Over the past century, human activities and their side effects have significantly threatened both ecosystems and resident species. Nevertheless, the genetic patterns of large felids that depend heavily on large and well-conserved continuous habitat remain poorly studied. Using the largest-ever contemporary genetic survey of wild jaguars (Panthera onca), we evaluated their genetic diversity and population structure in natural (Brazilian Amazon) and highly modified habitats (e.g. Cerrado, Caatinga) including those close to the northern (Yucatan, Mexico) and southern (Pantanal) edge of the species' distribution range. Data from our set of microsatellites revealed a pronounced genetic structure, with four genetically differentiated geographic areas. Geographic distance was not the only factor influencing genetic differentiation through the jaguar range. Instead, we found evidence of the effects of habitat deterioration on genetic patterns: while the levels of genetic diversity in the Amazon forest, the largest continuum habitat for the species, are high and consistent with panmixia across large distances, genetic diversity near the edge of the species distribution has been reduced through population contractions. Mexican jaguar populations were highly differentiated from those in Brazil and genetically depauperated. An isolated population from the Caatinga showed the genetic effects of a recent demographic decline (within the last 20-30 years), which may reflect recent habitat degradation in the region. Our results demonstrate that the jaguar is highly sensitive to habitat fragmentation especially in human-dominated landscapes, and that in Brazil, the existing but limited genetic connectivity in the central protected areas should be maintained. These conclusions have important implications for the management of wide-ranging species with high dispersal and low population density. The restoration of ecological connectivity between populations over relatively large scales should be one of the main priorities for species conservation.

Keywords: felid, elusive, habitat deterioration, connectivity, conservation 


\section{INTRODUCTION}

Human impacts on ecosystems have increased dramatically throughout the world over the last century. Anthropogenic modifications of habitat (i.e., loss and fragmentation) that impact population size and connectivity can result in genetic erosion, which may seriously compromise the fitness of populations and increase extinction risk (Saccheri et al. 1998; Ceballos et al., 2002; Frankham 2003, 2005; Reed et al. 2003; Palomares et al. 2012). In addition, the spatial distribution of populations and their dynamics may also be important in shaping the patterns of genetic diversity throughout a species' range. Models have suggested the vulnerability of natural populations would be determined in part by their spatial distribution (peripheral vs. core populations) because it directly influences the genetic variability and abundance of a species (Gyllenberg \& Hanski 1992). In this context, one can predict that at the scale of species spatial distribution, the most vulnerable populations would be in areas impacted by both the demographic effects (i.e., location at the edge of the species' range) and environmental deterioration (i.e., habitat fragmentation and loss). Genetic analyses may provide early warning signals for the demographic consequences of these processes and provide specific recommendations for the design of effective conservation strategies.

Large felids have extensive home ranges and usually depend on well-conserved continuous habitat for reproduction and dispersal. They are thus particularly vulnerable to habitat degradation (Crooks 2002). During the last century, most of these charismatic species have experienced declines in population size worldwide, and the accelerated human-mediated habitat degradation (i.e., loss and fragmentation) and synergic effects of direct persecution such as hunting may be severely threatening their long-term survival (Nowell \& Jackson 1996; Perez 2001; IUCN 2010). While population surveys of elusive carnivorous felid species are a challenge (Williams et al. 2002, Thompson 2004), genetic studies are even more limited by the difficulty of obtaining an adequate number of samples. As a result, the genetic patterns of many large felids and their responses to landscape scale habitat disturbance, including fragmentation and degradation, remain poorly studied. Improvements to noninvasive genetic testing through sampling of faeces can promote broader scale surveys in the near future (Janecka et al. 2008, Roques et al. 2011, 2012). However, to date genetic studies on declining populations of large carnivores are limited primarily to medium and small spatial scales, such as Amur tiger (Panthera tigris altaica, Henry et al. 2009, Alasaad et al. 2009), jaguar (Panthera onca, Eizirik et al. 2001, Moreno et al. 2006, Haag et al. 2010), leopards (Panthera pardus, Dutta et al. 2013) and tiger (Panthera tigris, Reddy et al. 2011, Joshi et al.2013, Sharma et al. 2013).

The jaguar is the largest felid in the American continent and the third-largest cat worldwide. Historically, its range encompassed a large area extending from the southwestern USA through the Amazon basin to the Rio Negro in Argentina, but today it occupies only about $50 \%$ of this range (Mittermeier et al. 1998, Zeller 2007; Sanderson et al. 2002; Figure 1). Years of poaching and livestock conflicts during the last century associated with massive rates of deforestation have reduced and severely fragmented the species' habitat and distribution (Zeller 2007). As a result, the IUCN classifies the jaguar as Near Threatened with declining population trends (IUCN, 2010). Most of the loss of range 
has occurred at the edges in northern Mexico and southerwestern United States, and northern Argentina (Sanderson et al. 2002). In Brazil, which constitutes approximately $50 \%$ of the current jaguar range (Zeller 2007), the Amazon rainforest and the Pantanal floodplains are thought to harbor the two largest continuous jaguar populations worldwide (Sanderson et al. 2002). However, there is extensive deforestation and development in Brazil, especially in the highly impacted southern Cerrado and Caatinga biomes, at the eastern limit of the jaguar distribution.

The first large-scale phylogeographic study of the jaguar was based on the analyses of mitochondrial DNA (mtDNA) control region sequences and 29 nuclear microsatellite loci of 44 individuals sampled from Mexico to southern Brazil (Eizirik et al. 2001). It revealed a low level of genetic differentiation in the species throughout its geographic range. This pattern of genetic homogeneity was interpreted as the result of a rather recent population expansion, about 300,000 years ago, followed by a history of demographic connectivity on a continental scale. The only partition observed between the northern and southern areas of the range was attributed to a reduced historical gene flow across the Amazon River, although such a reduced connectivity was not supported by a more recent study (Moreno et al. 2006).

The continued destruction and fragmentation of its habitat suggest that many jaguar populations likely became demographically isolated and genetically depauperated in recent years. It appears that past and recent large-scale habitat loss and fragmentation has been sufficiently strong to promote genetic differentiation of jaguars in the Atlantic forest regions (Haag et al., 2010). Therefore, it is critical to gain a better understanding of genetic patterns and recent demographic processes at both local and large scales and to compare core and peripheral populations within the distribution range of the species.

In this study we report on populations from Mexico and Brazil where jaguars are still found at high densities and in areas representing both highly modified peripheral and well as preserved core habitats. The results represent one of the most extensive genetic analyses of contemporary samples of jaguars to date. We assessed the genetic structure and diversity of jaguar populations from diverse areas, tested whether jaguars are still genetically connected throughout the entire distribution range, and evaluated the potential genetic consequences of habitat fragmentation on populations. Finally, we discuss the importance of potential corridors within Brazil and the Yucatan Peninsula in Mexico and the implications for conservation priorities.

\section{MATERIAL AND METHODS}

\section{Study areas, samples and genotyping}

Non-invasive genetic samples of jaguars were obtained by collecting faeces in several areas of Mexico and Brazil (Figure 1A, Table 1, and Supplementary Material S1, S2). We collected in six different areas 
in the Yucatan Peninsula, which is close to the northern limit of the jaguar's distribution and includes the largest remaining tract of tropical forest in Mexico. In Brazil, we sampled areas with relatively high densities of jaguars and large extensions of natural or semi-natural habitat, both in Pantanal and Amazon forests, and populations in the Cerrado and Caatinga biomes where the areas are highly modified, have a high human population density, and are less suitable for jaguars. Faeces were collected in four different areas in the Brazilian Amazon, which represents the largest area of relatively continuous jaguar habitat (Sanderson et al. 2002). Pantanal is used primarily for extensive cattle ranching, there is less affected by habitat fragmentation than areas with intensive agriculture. Sampling was carried out at the Caiman Ecological Reserve (PANT), a cattle ranch and ecotourism center located in the southern Pantanal (Mato Grosso do Sul State). The Cerrado biome, originally covered by extensive areas of neotropical savannas and dry forest, has been severely fragmented by the agricultural activities of the last 50 years. Samples were obtained around three areas located within the Cerrado, and along the Araguaia river: the Emas National Park (ENP), one of Brazil's largest reserves located in the transition area with the Amazon biome; in Tocantins State, the Araguaia national Park (ANP) and the Cantão State Park (CSP), the only large conservation unit where jaguars are protected. The Caatinga of eastern Brazil represents the eastern limit of jaguar distribution in South America (Sanderson et al. 2002) and one of the most fragmented habitat remnants of the species in Brazil. Unique to Brazil, the Caatinga is a large and one of the most diverse regions of dry forests and arid scrubland of the world, but the high human population density has completely or partially transformed over $50 \%$ of its area (Casteleti et al. 2000).

Sampling was carried out in one of the most important protected areas of the Caatinga, the Serra da Capivara National Park (CAPV). Sampling of faeces in all areas was conducted mostly during the dry season between 2007 and 2009 with the exception in the Adolfo Ducke Reserve (DUCK), where samples were also collected in 2004 and 2005. In all sites, faeces were collected by inspecting roads and trails frequently used by humans or animals, except in Parque Estadual do Cantão (CANT), Araguaia (ARAG), PANT, and PNEM where scat detector dogs were used to find samples (Vynne et al. 2011b). Faeces were collected in sterilized plastic vials with approximately $30 \mathrm{ml}$ of absolute alcohol, subsequently transferred to $100-\mathrm{ml}$ plastic jars containing silica pellets (Roeder et al. 2004), and stored at room temperature until DNA extraction. Most samples collected in the Amazon were put directly in silica gel without the first step involving an alcohol solution.

We also obtained blood samples from captured individuals (Table 1). Skin samples collected in 2007 were also obtained from ARAG, Brazil and from Ejido Caobas (CAOB) in Mexico. DNA isolation from blood, liver and skin samples followed a standard phenol-chloroform extraction protocol (Sambrook et al. 1989). DNA was extracted from faecal samples using protocols based on the GuSCN/silica method (Boom et al. 1990) as previously described in Roques et al. (2014). All scat samples collected in the wild were first screened for species identification using species-specific primers (Roques et al. 2011). Those samples belonging to jaguars were genotyped at a set of 11 microsatellite loci as described in Roques et al. (2014). Briefly, after scoring the alleles with GENEMAPPER version 4.0 
137

138

139

140

141

142

143

144

145

146

147

148

149

150

151

152

153

154

155

156

157

158

159

160

161

162

163

164

165

166

167

168

169

170

171

172

(Applied Biosystems), a unique consensus genotype was assigned to samples given a consensus criterion derived from that proposed by Taberlet et al. (1996) and based on the results of the four PCR replicates. The four genotype replicates were compared to the consensus genotype and the quality index value (QI) was calculated as described by Miquel et al. (2006). Full details on error rates, allelic dropout and false alleles are available in a previous paper (see Supplementary Material 1 in Roques et al. 2014.

\section{Population structure, size and gene flow}

To explore the genetic evidence for subdivision among jaguars, we first used the program STRUCTURE over the 14 locations and to identify populations within Brazil (BRAZ) or within Mexico (MEXC). Simulations were conducted by varying the number of genetic clusters ( $k=1-12$; alternatively, $k=1-7$ for within BRAZ and MEXC) with 30,000 steps of the Markov chain Monte Carlo (MCMC), following a burn-in period of 300,000 iterations, with and without a priori 'population' information. Twenty independent runs for each $\mathrm{k}$ were performed under an admixture model with correlated gene frequencies to determine the number of genetic clusters. The most likely number of $k$ was calculated based on $\Delta k$ as described in Evanno et al. (2005) and on visual inspection of the plot of $\operatorname{InP}(D)$ as a function of $k$, using STRUCTURE HARVESTER (Earl 2011). Once the number of $k$ was estimated, two replicates of a longer run with 300,000 steps of burn-in followed by 1,000,000 steps were performed to assign individuals to clusters. The partition of the total genetic variation into different genetic clusters was further assessed based on a Factorial Component Analysis (FCA) in GENETIX v.4.03 (Belkhir et al. 2004). The extent of genetic differentiation among the populations defined based on clustering approaches (see above) was estimated with FST statistics (Weir \& Cockerham 1984) using Genetix (5,000 permutations). Further, we tested whether patterns of neutral genetic structure were the product of isolation by distance. We calculated population-level pairwise genetic differentiation as FST/(1-FST) (Slatkin 1995) using Fst values calculated in Genetix (Belkhir et al. 2004). Geographic distance was calculated as the closest linear distance between pairs of sampling areas using Google Earth (http://earth.google.com). We tested whether genetic distance was related to geographic distance using Mantel tests, implemented in the program IBD (Isolation by Distance; Bohonak et al. 2002).

\section{Detection of migrants}

STRUCTURE 2.3.2 and GENECLASS 2.0 were also used to identify first-generation migrants and individuals with mixed ancestry. In STRUCTURE, prior population information was used in the USEPOPINFO option in to determine the individuals that were not residents of their sampled population. MIGPRIOR was set to 0.05 . GENECLASS 2.0 specifically identifies first generation migrants, i.e. individuals born in a population different to the one it was sampled (Paetkau et al. 2004; Piry et al. 2004). The Bayesian criterion of Rannala and Mountain in combination with the resampling method of 
173

174

175

176

177

178

179

180

181

182

183

184

185

186

187

188

189

190

191

192

193

194

195

196

197

198

199

200

201

202

203

204

205

206

207

208

209

Paetkau and an alpha level of 0.05 were used to determine critical values. We used a Lh/Lmax likelihood $>0.60$ to statistically identify migrants.

\section{Genetic diversity}

Diversity parameters were first calculated for the pre-defined populations. Departures from linkage disequilibrium and the Hardy-Weinberg equilibrium (HWE) were tested using exact tests as implemented in GENEPOP on the web (Rousset 2008). Genetic diversity was assessed through the observed and expected heterozygosity ( $\mathrm{HO}$ and $\mathrm{HE}$ ) estimated using GENETIX. Further, allelic richness (i.e., the number of alleles per locus independent of sample size) and percentage of shared and private alleles were calculated using the program HPrare (Kalinowski 2005). Differences of indices among populations were tested with Wilcoxon signed-rank tests.

\section{Population size reductions}

We used two different approaches to test for a genetic bottleneck signature. Because violations of the panmixia assumption might bias these tests, genetic homogeneity within the pre-defined population units was confirmed based on both FST statistical significance (see Supplementary Material S1) and Structure approaches (see above). For the first approach, the mutation-drift equilibrium test which is implemented in BOTTLENECK 1.2.02 (Cornuet \& Luikart 1996, Piry et al. 1999), tests whether the number of loci with heterozygosity excess is significantly higher than that expected by chance at mutation-drift equilibrium. In populations that have experienced a relatively recent (within the last $\sim 0.2-4 \mathrm{Ne}$ generations) reduction in effective size, the number of alleles is reduced faster than gene diversity, leading to a transient excess of heterozygosity (Luikart \& Cornuet1998). The program was initially run under either the $100 \%$ infinite alleles model (IAM) or stepwise mutation model (SMM) of microsatellites evolution. In order to test the sensitivity of the analysis to the mutation model chosen, we ran the program under a two-phase mutation model (TPM model) because the microsatellites in this study are dinucleotide repeats, which better fit the IAM (Cornuet \& Luikart 1996). We ran the program with proportions of either $5 \%$ or $30 \%$ of SMM. Significance was assessed from 10,000 iterations using a Wilcoxon signed-rank test which give the highest statistical power when population sample size is small (30 or fewer) (Cornuet \& Luikart 1996). For the second approach, we used the M-ratio (Garza \& Williamson 2001) which corresponds to the mean ratio of the number of alleles to the allele size range across all loci, and the value is expected to decrease following a population reduction. The M-ratio test is more sensitive than the other two tests and would detect a bottleneck signal longer after it occurred, and thus gives insights into population contractions occurring at a larger timescale. M-ratios were calculated using AGARST (Harley 2002) and the critical M-ratio (Mcrit) for each sample location was determined using the critical_M.exe software (Garza \& Williamson 2001). We set the mean number of non-one-stepwise mutations (ps) to 0.12 and the mean size of larger mutation (thetaS) as 2.8 as conservative parameters (i.e., lower critical value), as suggested by the authors. Pre-bottleneck values were calculated using $\alpha=5 \times 10^{-4}$ (Garza \& Williamson 2001) and Ne values estimated in this study for the jaguar, as well as several Ne values 
(i.e., 20, 50, 150, 300). Two loci with odd-sized alleles (those that did not represent multiples of the recognized repeat unit) were omitted from these analyses (FC115 and FC566).

To estimate the effective size $(\mathrm{Ne})$ in our populations, we first applied the linkage disequilibrium method using the program LDNE (Waples \& Do 2008), assuming random mating and excluding all alleles with frequencies lower than 0.02. We also used an Approximate Bayesian Computation (ABC) approach as implemented in the program ONESAMP (Tallmon et al. 2008), which is considered more robust and less biased by substructure and overlapping generations than LDNE (Luikart et al. 2010).

In order to test the genetic effects of recent habitat degradation in the southeastern Brazilian areas and especially the probable recent isolation of the Caatinga population, we used a coalescent-based MCMC simulation implemented in 2MOD (Ciofi et al. 1999). This method tests whether the observed population structure would better fit a gene flow-drift equilibrium model or a pure drift model; the first model assumes a balance between gene flow and drift (i.e., populations at equilibrium) while the second model assumes that an ancestral panmictic population has evolved into several different units diverging by drift in the absence of gene flow. The MCMC search was carried out twice for $30 \times 105$ iterations with the first $3 \times 104$ discarded as burn-in. The posterior distribution of $\mathrm{F}$ (probability of coancestry of any two genes in the putative population) was estimated for each population. Simulations were run with 600,000 steps with a burn-in of 100,000 in three independent runs. We used Tracer v 1.40 (http://beast.bio.ed.ac.uk/) to evaluate the stationarity of model parameters, verify adequate sample sizes, determine an appropriate amount of burn-in, and verify the consistency between runs. Under the drift model, we estimated the time since isolation among the three areas relative to the population size, (T/N) as - $\log (1-\mathrm{F})$, following Ciofi et al. (1999).

\section{RESULTS}

\section{Non-invasive genetics}

We successfully determined the species for $73 \%(\mathrm{~N}=473)$ of 651 faecal samples collected and processed (Table 1). Most of the faecal samples were from jaguars (49.7\%) and pumas (41.6\%), and to a lesser extent, smaller felids (ocelot/margay; 8.7\%). Among the 234 jaguar faecal samples, a high proportion (91\%) have $\geq 50 \%$, quality (based on the Quality Index; Ql; Miquel et al. 2006) and 71\% of genotypes have even higher quality ( $\mathrm{QI} \geq 75 \%)$. Consensus multilocus genotypes for each sample were grouped into 62 different genotypes representing distinct individuals following the assignment strategy described by Roques et al. (2014). Including the genotypes obtained from high quality DNA sources (blood: $n=31$; liver: $n=13$, and skin: $n=7$ ) we gathered 102 distinct genotypes from 14 study areas across the current distribution range of the jaguars (Table 1 and Supplementary Material S3).

\section{Genetic differentiation and connectivity}


The overall genetic differentiation was high and jaguar populations were genetically structured throughout the species' range. Within Brazil, Fst values were low and not significantly different from zero among the four Amazonian localities (DUCK, UATM, VIRU, MARA) and among all central areas along the Araguaia river (CANT, ARAG, PNEM), but they were high and significant among the other populations studied (see Supplementary Material S1). Based on these results, we defined four differentiated genetic entities within Brazil (Table 1): AMZN (Amazon - DUCK, UATM, MARC, and VIRU); PANT (Pantanal); CAPV (Caatinga); and an intermediate area in the central region, namely CENTR (ARAG, CANT, and PNEM). Within the Yucatan Peninsula, estimates of genetic differentiation (Fst) were low and not significant for any pairwise comparison, thus corroborating genetic homogeneity at this scale. Differentiation among the inferred genetic units was very high and significant for comparisons between Brazil (PANT, CAPV, AMZN, CENT) and MEXC (Table 2; P $\leq 0.01$ ), indicating high divergence in allele frequencies between these geographically distant areas. Within Brazil, the highest value occurred with comparisons involving CAPV and the other sampling areas, while differentiation between CENT and the rest of the populations was lower and the differentiation between AMZN and CENT was not significant (Table 2).

A significant positive correlation between genetic and geographic distance was observed among the jaguar populations at both large (Figure $2 \mathrm{~A}$; Mantel test, $r=0.655, \mathrm{P}<0.001$ ) and regional (Figure 2B; Mantel test, $r=0.5232, P<0.019)$ scales. The result of this test showed that a considerable part of the genetic variation was explained by geographic distance. Within Brazil, these results supported the Factorial Component Analysis (Figure 3B) since all geographically-close populations resembled each other. Also, we found that almost all comparisons involving CAPV (Figure 2B, grey circles) stand above the line, corroborating that this area presents more differentiation with the other areas than expected by distance only.

The STRUCTURE analysis including all samples suggested $\mathrm{K}=4$ as the most likely number of genetic clusters (Figure 3A and Supplementary Material S4 for Evanno'S output table for all K values). The geographical samples with predominant membership in the four clusters were grouped into Mexico (MEXC: ZAPT, EDEN, CAOB, CALAK, mean $Q=0.66$ ); Amazon (AMZN: MARA, VIRU, DUCK, UATM, mean $Q=0.84$ ), Caatinga (CAPV mean $Q=0.71$ ) and Pantanal (PANT mean $Q=0.72$ ). When the Mexican areas were analyzed separately, a single and panmictic population (MEXC, K =1) (results not shown) was the most likely scenario. Within Brazil, $\mathrm{K}=3$ was the most likely number of genetic clusters. These three clusters correspond to the three distinct geographical areas of PANT, AMZN and CAPV. The individuals from the central localities CENT, namely CANT, ARAG, PNEM, cluster with individuals from AMZN, but show some ancestry in the other two populations (Figure $3 \mathrm{~A}$ ).

The representation of all individuals in the Factorial Correspondence Analysis was also highly congruent with the above clustering, clearly depicting the divergence of Mexican areas and the existence of three genetic entities in Brazil (CAPV, PANT, AMZN) and with CENT individuals occupying intermediate positions between these (Figure $3 \mathrm{~B}$ ). The analyses clearly illustrated that CAPV is highly 
genetically intermediate between those from AMZN and those from southern (PANT) and eastern (CAPV) populations.

\section{Identification of migrants and admixed individuals within Brazil}

We identified a total of 18 migrants in Brazil (Table 4). Most of them $(n=14)$ were sampled in central areas (CENT), while two in PANT, one in AMZN and one in CAPV. STRUCTURE and GENECLASS were concordant in detecting six first-generation migrants (i.e. not born in the sampled area), all from CENTR ( $n=2$ in ARAG and 4 in PNEM). STRUCTURE also identified two individuals (CANT_H3-28 and PANT_SGH27) that were neither readily classified as migrants nor as residents ( $Q$-values $<0.60$ ) suggesting that they might be of admixed ancestry (Table 3 ).

\section{Genetic diversity and population demography}

None of the populations showed significant HWE disequilibrium after Bonferroni correction ( $\leq \leq 0.001)$. Also, only two out of 55 tests for Linkage disequilibrium LD were statistically significant after applying the Bonferroni correction. Those tests involved different pairs of loci and occurred in different populations, suggesting that the assayed loci assorted independently. Mean expected and observed heterozygosities across loci and samples were 0.800 and 0.730 , respectively. Both heterozygosity and allele number were higher in Brazil (mean $\mathrm{He}=0.812$, mean $\mathrm{A}=9.45$ ) than in Mexico (mean $\mathrm{He}=$ $0.634, A=4.45$ ) (Table 3). Expected heterozygosity, He, calculated for the genetic clusters identified above, ranged from 0.654-0.805, with values significantly higher in AMZN (Wilcoxon sign-rank test, P $\leq$ $0.03)$ and lower in MEXC ( $P \leq 0.03)$ than in the other areas. However, the difference between MEXC and CAPV was not significant $(P=0.22)$. Allelic richness was also highest for $A M Z N(P \leq 0.02)$ and lowest for MEXC and CAPV (Table 3). The allelic richness in PANT was moderate and not significantly different from the values found in $\operatorname{MEXC}(P=0.09)$ and CAPV $(P=0.22)$. The jaguar population at CAPV had the lowest proportion of private alleles (4\%) in Brazil, less than half of that found for AMZN, and the population at CENT shared the highest proportion of alleles with the other studied populations (74\%, 69\% and 63\% for AMZN, PANT, and CAPV, respectively). While the highest effective population size was estimated for AMZN (>250), the effective population sizes were much lower for the remaining populations (between 13 and 30) (Table 3). When we applied BOTTLENECK, we observed clear signatures of recent bottlenecks for both MEX and CAPV under IAM ( $<<0.05)$ and TPM with either SMM $=5 \%$ or $70 \%$ (see Table 3). However, all tests were non-significant under SMM. Among all populations sampled, the $\mathrm{M}$-ratio ranged from $0.670(\mathrm{Cl}=0.057)$ to $0.888(\mathrm{Cl}=0.041)$, with the lowest values found in CAPV and PANT (Table 3). However, only the value for CAPV was lower than almost the whole range of simulated critical values (Mcrit20 $=0.662$, Mcrit50 $=0.650$, Mcrit150 = 0.629 , and Mcrit300 $=0.600$ ), suggesting a stronger reduction in size of this population than in the other populations. In contrast, the M-ratio of MEXC was high (0.888) and contrasts with the highly significant $P$ value when BOTTLENECK was applied; these values suggest a more recent population contraction event in this region (Cornuet \& Luikart 1996). 
Using the 2Mod program, we evaluated the alternative hypotheses of whether the isolation of the Caatinga population was the result of a recent isolation (i.e., the pure drift model) or if this reflected an equilibrium situation of an historically small and weakly connected population (i.e., the gene flow-drift equilibrium model). The results of $2 \mathrm{Mod}$ overwhelmingly supported a pure-drift rather than a migration-drift equilibrium scenario $(P($ drift model $)=0.9)$ for the CAPV, AMZN, CENT populations. Under the drift model, we calculated F values (FCAPV $=0.1481,95 \% \mathrm{Cl}$ : 0.1361-0.1494; FAMZN $=0.0741,95 \% \mathrm{Cl}: 0.0 .0737-0.0746$; FCENT $=0.0531,95 \% \mathrm{Cl}: 0.0 .0536-0.0541)$ and the T/N was estimated to be $0.1602(2 \mathrm{Ne}=28)$ for CAPV; $0.0544(2 \mathrm{Ne}=400)$ for CENT; and $0.0768(2 \mathrm{Ne}=596)$ for AMZN. Based on a generation time of five years and the effective population size estimates (reported here), these values suggest the population in CAPV has been isolated for approximately 20 years.

\section{DISCUSSION}

\section{Genetic effects of habitat deterioration and biogeography}

Our study examined genetic diversity and connectivity of jaguars on a large spatial scale in Mexican and Brazilian ecosystems. The results indicate that despite prior evidence for historical connectivity and panmixia (Eizirik et al. 2001, Table 5), the jaguar is genetically structured throughout its range. While genetic differentiation of areas of the jaguar distribution range is primarily driven by isolation resulting from distance (Figure 3) and putative barriers to gene flow (e.g., Amazon River, Darien Straits; Eizirik et al. 2001), the recent habitat deterioration (i.e., habitat fragmentation and loss) may have caused a disruption of gene flow and an intensification of genetic drift in part of its range. The population of Capivara in the eastern edge of the species distribution is separated by a large area of unsuitable habitat, suggesting that such barrier may further contribute to genetic divergence and to the pronounced genetic isolation found in this area.

Our results are similar to those reported by Eizirik et al. (2001) for the same area and show that the genetic diversity values in Mexico are some of the lowest reported for the species (Table 5). The low diversity and high differentiation for this particular region may be attributable to the recent colonization of jaguar populations in the northern areas and to a global pattern of isolation by distance (Eizirik et al. 2001). However, the significant signs of recent bottlenecks found in this region suggest that individuals from the Mexican population might be exhibiting the genetic signals of recent anthropogenic perturbations and isolation. This area is situated close to the northern limit of the species' range and is probably more vulnerable to stochastic demographic effects (Vucetich \& Waite 2003; Chavéz et al. 2005). Additionally, the Yucatan Peninsula population is connected northward to areas with groups of individuals that occur at the lowest densities reported for jaguars, including the relict populations of Sinaloa and Baja California (Navarro-Serment et al. 2005, Rosas-Rosas \& Bender 2012) (see Figure 1A). Jaguars have been extirpated to the south of the Yucatan, in parts of Nicaragua 
and Honduras, and this loss may have disrupted the gene flow with individuals from further south (Sanderson et al. 2002).

Genetic evidences for the effects of recent isolation were compelling for the Caatinga (CAPV) population. All population structure analyses indicated increased genetic drift and reduced gene flow between CAPV and the other regions. A significant reduction of diversity is reflected in low values of allelic richness (Table 4 ), whereas both estimates of heterozygosity were close to those estimated previously for the species ( $\mathrm{He}=0.732$ in Haag et al. 2010 and $\mathrm{He}=0.724$ in Eizirik et al. 2001), but lower than those in the Amazonian strongholds (Table 5). This difference may be a reflection of the generally faster response of allelic richness to population contractions than heterozygosity (Cornuet $\&$ Luikart 1996, Srikwan \& Woodruff 2000), with the former being thus a more sensitive signal of recent genetic erosion in isolated populations. The preponderance of genetic drift and the increased isolation of the CAPV population in recent times are also supported by the selection of a pure-drift model by the coalescent-based simulations. The Bayesian approach suggests a very recent (about 20 years) genetic isolation of the CAPV population, while jaguars from the Amazon and Cerrado regions probably were well connected until 100 years ago. This observation, along with the low proportion of private alleles in CAPV and the fact that it shares a major proportion of its alleles with the central areas, corroborates historical evidence that CAPV was once part of a much larger population that included the Cerrado.

The detection of two migrants from PNEM (assigned to CAPV), and a single one in CAPV (assigned to $A M Z N)$, is thus consistent with restricted connectivity and disturbed potential corridors recently described in this area (Silveira et al. 2014 and Figure 1B). The Cerrado biome, which marks the transition between the Amazon and the southern populations, has been intensively modified since the 1950s through extensive cattle farming and agricultural monocultures (rice, corn, soybean), and today up to $80 \%$ of this region is considered degraded (Cavalcanti \& Joly, 2002). The isolation of the jaguar population in the Caatinga may have been driven in the last few decades by the lack of suitable habitat for connectivity with surrounding populations. The relatively low estimate of effective population size calculated for CAPV is supported by results of recent field studies in the region. While the Capivara National Park is considered to have an important jaguar population (Silveira et al. 2010), substantial contractions as the result of habitat changes, scarcity of prey and persecution have been reported recently in the Brazilian Caatinga (Sollman et al. 2008). The semiarid climate and poor soil limit large scale agriculture and cattle ranching, and about $60 \%$ of this area still maintains the native vegetation cover, although as fragmented blocks (Castelletti et al. 2000). The low estimated effective population size suggests that further genetic erosion will occur until the population size or the gene flow from other regions increases (Frankham et al. 1999, England et al. 2010, Palomares et al. 2012). Jaguar populations in other Brazilian areas (AMZN, CENT, PANT) were generally more diverse than the ones at the northern and eastern limits of the species range (MEXC, CAPV). The Amazon was the most genetically diverse region and had the highest proportion of private alleles, and variability indices were comparable to values found in other tracts of forest in Colombia, Bolivia, and Peru (Table 5). 
Many areas in the Amazon are still connected, forming enormous blocks of evergreen forest that support large effective populations (Oliveira et al. 2012) and panmictic breeding, and our estimate of a moderate to large effective population size agrees with that reported in this biome (Sollmann et al. 2008).

Results for the Pantanal region indicate that even though population bottlenecks were not statistically detectable, this area may be showing early signs of genetic erosion and isolation. Allelic richness and heterozygosity in the population from the Caiman Ecological Reserve were medium to low (Table 4) and close to those found in the nearby area of the Upper Parana (Haag et al. 2010, Table 5). These results were striking for several reasons: as the largest seasonally flooded landlocked area in the world, the Brazilian Pantanal still is covered by native vegetation over most of its territory and relatively well-connected; the extensive cattle ranching on native pastures (Harris et al. 2005) has maintained some level of habitat quality for jaguars and has provided them with additional sources of prey (Swartz 2000), what may explain the reported high jaguar density (Soisalo \& Cavalcanti 2006), even in non-protected areas. However, in some areas of this biome, the genetic patterns we detected in our research support the observations made in earlier work (Altrichter et al. 2006), namely a decrease in the size of some populations and increased isolation. These results are not unexpected because some intensive cattle ranching practices have resulted in a major loss of native habitat and increased direct persecution (i.e., hunting) of jaguars resulting from the increased conflict with cattle ranchers (Crawshaw \& Quigley 2002). Additionally, populations in the southern Pantanal are connected southwards with the Atlantic forest region, a heavily human-impacted biome where jaguar populations also show clear signs of genetic isolation and loss of genetic diversity (Haag et al. 2010). The results of our work can serve as a starting place for discussion and evaluation of the role of the Pantanal as a secure refuge for jaguars.

\section{The importance of connectivity for jaguar conservation}

The population structure observed at this scale intimate that connectivity with the extreme eastern (i.e., Caatinga) and southern areas (i.e., Pantanal) is limited (Table 2) and that much of the existing connectivity may be at risk because of continued habitat erosion, and might be enhanced through habitat restoration or genetic exchange among them.

Interestingly, our research suggests that the central areas of Brazil within the Cerrado region (PNEM, ARA and CANT) (Figure 1A), may act as "stepping stones" to maintain connectivity between the Amazon and the surrounding eastern and southern populations. The identification of at least 6 firstgeneration migrants in these central areas coming from all others areas ( 2 from CAPV, 2 from AMZN and 2 from PANT) pointed out that movements and reproduction while limited, may have occurred in the recent past at this scale. The significant Isolation by Distance pattern, along with the lowest genetic differences observed between the populations in the central areas and other areas in Brazil (Table 2 and Figure 2B, 3B) also suggests that CENT, AMZN and CAPV populations were probably connected recently. Our study thus highlights the significant potential of the Araguaia River, 
430

431

432

433

434

435

436

437

438

439

440

441

442

443

444

445

446

447

448

449

450

451

452

453

454

455

456

457

458

459

460

461

462

463

464

465

considered as the most important biodiversity corridor in central Brazil, which flows from the center of the Cerrado to the Amazon and into the Tocantins River (see Figure 1A), for the maintenance of diversity and connectivity among jaguar populations in Brazil, as suggested recently (Silveira et al. 2014) and in earlier works (Negroes et al. 2011, Vynne et al. 2011a).

The restoration of ecological connectivity between populations over relatively large scales should be one of the main priorities for the conservation of the jaguar and for other wide-ranging species with high dispersal, low population density and that are particularly vulnerable to anthropogenic impacts. We stress the importance of ambitious programs to conserve a continuous north to south habitat corridor through the range of the species (Rabinowitz \& Zeller 2010 and Figure 1B) and to evaluate the potential for large scale jaguar corridors in Brazil (Silveira et al, 2014).

\section{Implications for species viability, conservation and management}

Our work showed that genetic patterns differed among jaguar populations and biomes but were highly consistent with the known status of the populations as well as with the degree of habitat deterioration and connectivity with neighboring populations. Large continuous forested areas, such as the Amazon, still maintain genetically healthy jaguar populations. In contrast, the geographic and genetic isolation of the Caatinga population suggests that the jaguar may be at risk of extinction in those areas of its range not connected, and especially those near the edge, or those which may become isolated in the near future by the high rates of fragmentation. With the exception of the groups in the Amazon, estimates of effective population sizes were low ( $N=13$ to 30 ) and much below the number of 85 individuals proposed as the minimum threshold for long-term population viability (>200 years; Sollmann et al. 2008). These low population values reinforce other evidence showing a continued trend of declining jaguar populations. While large carnivores with widespread geographic ranges should be at lower risk from habitat fragmentation, our research showed that jaguar connectivity may be limited by the difficulty of dispersing in modified habitats. In a changing landscape, protection and/or establishment of reserves are one of the most important tools for habitat preservation as a buffer against anthropogenic impacts (Noss et al. 1996, Margules \& Pressey 2000, Rylands \& Brandon 2005, Shivik 2006). In Brazil, a system of connected protected areas extensive enough to hold long-term viable jaguar populations is currently implemented in the Amazon, but it is absent in other important jaguar areas such as the Caatinga biome. Long-term jaguar conservation may depend on alternative strategies integrating non-protected landscapes, as well as cultural and political mechanisms (Sollmann et al. 2008).

\section{ACKNOWLEDGEMENTS}

This study was carried out with the support of the project BIOCON 05 - 100/06 of the Fundación BBVA, the project CGL2010-16902 of the Spanish Ministry of Research and Innovation, the project CGL2013-46026-P of MINECO, the excelence project RNM 2300 of the Junta de Andalucía, 
492

493

494

495

496

497

498

499

500

501

and projects UAM-PTC-333 and PROMEP/103.5/12/3823. Sampling in the Mexican areas under the licence SGPA/DGVS/549 provided by Martín Vargas of the Dirección General de Vida Silvestre (Semarnat). Faecal samples were exported from Mexico to Spain under the export licences no MX33790 and MX42916 of the Secertaria de Medio Ambiente/CITES. Sampling in Brazil was carried out in RAPELD sites installed or maintained by the Brazilian Program for Biodiversity Research (PPBio) and under licenses \#131/2005 CGFAU/LIC, 13883-1 SISBIO and 15664-1 SISBIO of the Instituto Brasileiro do Meio Ambiente - IBAMA. Faecal samples were exported from Brazil to Spain for genetic analysis under IBAMA/CGEN Autorização de Acesso license \#063/05 and IBAMA/CITES export licenses \#0123242BR and 08BR002056/ DF". We thank the management of the Edén Ecological Reserve (Marco Lazcano) and El Zapotal Ecological Reserve (Pronatura Península de Yucatán: Juan Carlos Faller and María Andrade) for their logistical support. We are grateful to J.S. Lópes and J. Tavares for the collection of most of the field samples in Brazil. Julia Martínez, Gloria Clemencia Amaya, Juan Carlos Faller, Meredic Calleja and Ana Alicia Morales helped with the fieldwork in Brazil and Mexico, as well as the local reserve staff of El Zapotal and El Edén (Mexico). L. Soriano and A. Piriz provided technical advice on multiple issues, and A. García, E. Marmesat, and B. Gutiérrez assisted in the analysis of samples. Logistical support was provided by Laboratorio de Ecología Molecular, Estación Biológica de Doñana, CSIC (LEM-EBD). The Spanish Ministry of Education and Sciences supported the visit of S. Roques in Mexico. We thank Manuela Gonzalez-Suarez and Philip Hedrick for an early revision of the manuscript.

\section{REFERENCES}

Alasaad, S, Soriguer RC, Chelomina G, et al. (2011) Siberian tiger's recent population bottleneck in the Russian Far East revealed by microsatellite markers. Mammalian Biology 76, 721- +.

Altrichter M, Boaglio G, Perovic P. (2006) The decline of jaguars, Panthera onca, in the Argentine Chaco. Oryx 40, 302-309.

Belkhir K, Borsa P, Chikhi L, Raufaste N, et al. (2004) Genetix 4.05: logiciel sous WindowsTM pour la génétique des populations. Laboratoire Génome, Populations, Interactions, CNRS UMR 5000. Montpellier, France: Université de Montpellier II.

Bohonak, A. J. 2002. IBD (Isolation By Distance): A program for analyses of isolation by distance. Journal of Heredity. 93, 153-154

Boom R, Sol CJa, Salimans MMM, et al. (1990) Rapid and Simple Method for Purification of Nucleic-Acids. Journal of Clinical Microbiology 28, 495-503. 
Casteleti CHM, Silva JMC, Tabarelli M, Santos AMM (2000) Quanto resta da Caatinga? Uma estimativa preliminar. In: J. M. C. Silva \& M. Tabarelli (coord.), Workshop Avaliação e identificação de ações prioritárias para a conservação, utilização sustentável e repartição de benefícios da biodiversidade do bioma Caatinga, www.biodiversitas.org.br./caatinga.

Cavalcanti RB, Joly CA (2002) Biodiversity and Conservation Priorities in the Cerrado Region. In: The Cerrados of Brazil. Ecology and Natural History of a Neotropical Savanna. Oliveira, PS and Marquis, RJ (Eds.). Columbia University Press, New York, pp 351-367.

Ceballos, G., C. Chávez, A. Rivera y C. Manterola. 2002. Tamaño poblacional y conservación del jaguar (Panthera onca) en la Reserva de la Biosfera Calakmul, Campeche, México. Pp. 403 - 481, en: Jaguares en el nuevo milenio: Una evaluación de su estado, detección de prioridades y recomendaciones para la conservación de los jaguares en América. (Medellin, R. A., C. Chetkiewicz, A. Rabinowitz, K. H. Redford, J. G. Robinson, E. Sanderson, y A. Taber, Eds.). Universidad Nacional Autónoma de México/Wildlife Conservation Society. México D. F.

Chávez C, Arana M, Ceballos G (2005) Panthera onca. Pp. 367-370. In: Los mamíferos silvestres de México. Ceballos $\mathrm{G}$ and Oliva G (Eds.). CONABIO - UNAM - Fondo de Cultura Económica, México D.F.

Ciofi C, Beaumont MA, Swingland IR, et al. (1999) Genetic divergence and units for conservation in the Komodo dragon, Varanus komodoensis. Proceeding of the Royal Society of London Series B. Biological Sciences 266, 2269-2274.

Cornuet JM, Luikart G (1996) Description and power analysis of two tests for detecting recent population bottlenecks from allele frequency data. Genetics 144, 2001-2014.

Crawshaw Jr. PG, Quigley HB (2002) Hábitos alimentarios del jaguar y el puma en el Pantanal, Brasil, con implicaciones para su manejo y conservación. In: El Jaguar en El Nuevo Milenio. Medellín RA, Equihua C, Chetkiewitcz C LB, Crawshaw Jr. PG, Rabinowitz A, Redford KH, Robinson JG, Sanderson EW and Taber AB (Eds.). Fondo de Cultura Económica, México, Universidad Nacional Autónoma de México, México, Wildlife Conservation Society, New York, pp. 223-236.

Crooks KR (2002) Relative sensitivities of mammalian carnivores to habitat fragmentation. Conservation Biology 16,488-502.

Dutta, T., Sharma, S., Maldonado, J. E., Wood, T. C., Panwar, H. S., Seidensticker, J. (2013) Gene flow and demographic history of leopards (Panthera pardus) in the central Indian highlands. Evolutionary Applications. doi: 10.1111/eva.12078 (Selected as cover page article). 
551

552

553

554

555

556

557

558

559

560

561

562

563

564

565

566

567

568

569

570

571

572

573

574

575

576

577

578

579

580

581

582

Earl DA, vonHoldt BM (2011) STRUCTURE HARVESTER: a website and program for visualizing STRUCTURE output and implementing the Evanno method. Conservation Genetics Resources DOI: 10.1007/s12686-011-9548-7. Version: v0.6.8.

Eizirik E, Kim JH, Menotti-Raymond M, et al. (2001) Phylogeography, population history and conservation genetics of jaguars (Panthera onca, Mammalia, Felidae). Molecular Ecology 10, 6579.

England PR, Luikart G, Waples RS (2010) Early detection of population fragmentation using linkage disequilibrium estimation of effective population size. Conservation Genetics 11, 2425-2430.

Evanno G, Regnaut S, Goudet J (2005) Detecting the number of clusters of individuals using the software STRUCTURE: a simulation study. Molecular Ecology 14, 2611-2620.

Frankham R, Lees K, Montgomery ME, et al. (1999) Do population size bottlenecks reduce evolutionary potential? Animal Conservation 2, 255-260.

Frankham R (2003) Genetics and conservation biology. Comptes Rendus Biologies 326, S22-S29.

Garza JC, Williamson EG (2001) Detection of reduction in population size using data from microsatellite loci. Molecular Ecology 10, 305-318.

Gyllenberg M, Hanski I (1992) Single-Species Metapopulation Dynamics: A structured model. Theoretical Population Biology 42, 35-62.

Haag T, Santos AS, Sana DA, et al. (2010) The effect of habitat fragmentation on the genetic structure of a top predator: loss of diversity and high differentiation among remnant populations of Atlantic Forest jaguars (Panthera onca). Molecular Ecology 19, 4906- 4921.

Harley EH (2002) AGARST, version 2.8. A program for calculating allele frequencies, GST and RST from microsatellite data. Wildlife Genetics Unit, University of Cape Town, South Africa.

Harris MB, Tomas W, Mourão G, et al. (2005) Safeguarding the Pantanal Wetlands: Threats and Conservation Initiatives. Conservation Biology 19, 714-720.

Henry P, Miquelle D, Sugimoto T, et al. (2009) In situ population structure and ex situ representation of the endangered Amur tiger. Molecular Ecology 18, 3173-3184.

IUCN, 2010. "IUCN SSC/Cat Specialist Group" (On-line). Accessed March 29, 2011 at 
Janecka JE, Jackson R, Yuquang Z, et al. (2008) Population monitoring of snow leopards using 587

601

602

603

Kalinowski ST (2005) HP-RARE 1.0: A computer program for performing rarefaction on measures of allelic richness. Molecular Ecology Notes 5, 187-189.

Luikart G, Cornuet JM (1998) Empirical evaluation of a test for identifying recently bottlenecked populations from allele frequency data. Conservation Biology 12, 228-237.

Luikart G, Ryman N, Tallmon DA, Schwartz MK, Allendorf FW (2010) Estimation of census and effective population sizes: the increasing usefulness of DNA-based approaches. Conservation Genetics 11, 355-373.

Margules CR, Pressey RL (2000) Systematic Conservation Planning. Nature 405, 243-253.

Miquel C, Bellemain E, Poillot C, et al. (2006) Quality indexes to assess the reliability of genotypes in studies using non-invasive sampling and multiple-tube approach. Molecular Ecology Notes 6, 985988.

Mittermeier RA, Myers N, Thomsen JB, da Fonseca GAB, Olivieri S (1998) Biodiversity hotspots and major tropical wilderness areas: Approaches to setting conservation priorities. Conservation Biology 12, 516-520.

Moreno VR, Grisolia AB, Campagnari F, et al. (2006) Genetic variability of Herpailurus yagouaroundi, Puma concolor and Panthera onca (Mammalia, Felidae) studied using Felis catus microsatellites. Genetics and Molecular Biology 29, 290-293.

Navarro-Serment CJ, Lopez-Gonzalez CA, Gallo-Reynoso JP (2005) Occurrence of jaguar (Panthera onca) in Sinaloa, Mexico. Southwestern Naturalist 50, 102-106.

Negroes N, Revilla E, Fonseca C, et al. (2011) Private forest reserves can aid in preserving the community of medium and large-sized vertebrates in the Amazon arc of deforestation. Biodiversity and Conservation 20, 505-518. 
631

632

633

634

635

636

637

638

639

640

641

642

643

644

645

646

647

648

649

650

651

652

653

654

655

656

657

658

659

660

661

Noss R, Quigley HB, Hornocker MG, et al. (1996) Conservation Biology and Carnivore Conservation in the Rocky Mountains. Conservation Biology 10, 949-963.

Nowell K, Jackson P (1996) Wild Cats: status survey and conservation action plan. IUCN/SSC Cat Specialist Group, Gland, Switzerland, 406 pp.

Oliveira de TG, Ramalho EE, de Paula RC (2012) Red List assessment of the jaguar in Brazilian Amazonia. CATnews Special Issue 7.

Paetkau, D., Slade, R., Burden, M. \& Estoup, A. (2004) Genetic assignment methods for the direct, realtime estimation of migration rate: a simulation-based exploration of accuracy and power. Molecular Ecology, 13, 55-65.

Palomares F, Godoy JA, Lopez-Bao JV, et al. (2012) Possible Extinction Vortex for a Population of Iberian Lynx on the Verge of Extirpation. Conservation Biology 26, 689-697.

Perez CA (2001) Synergistic effects of subsistence hunting and habitat fragmentation on Amazonian forest vertebrates. Conservation Biology 15, 1490-1505.

Piry S, Luikart G, Cornuet JM (1999) BOTTLENECK: A computer program for detecting recent reductions in the effective population size using allele frequency data. Journal of Heredity 90, 502-503

Piry, S., Alapetite, A., Cornuet, J.M., Paetkau, D., Baudouin, L. \& Estoup, A. (2004) GENECLASS2: a software for genetic assignment and first-generation migrant detection. Journal of Heredity, 95, 536-539.

Rabinowitz A, Zeller KA (2010) A range-wide model of landscape connectivity and conservation for the jaguar, Panthera onca. Biological Conservation 143, 939-945.

Reddy PA, Kumaraguru A, Yadav PR, et al. (2011) Studies to determine presence or absence of the Indian tiger (Panthera tigris tigris) in Kawal Wildlife Sanctuary, India. European Journal of Wildlife Research 57, 517-522.

Reed DH, Lowe EH, Briscoe DA, Frankham R (2003) Inbreeding and extinction: Effects of rate of inbreeding. Conservation Genetics 4, 405-410.

Roeder AD, Archer FI, Poiner HN, Morin PA (2004) A novel method for collection and preservation of faeces for genetic studies. Molecular Ecology Notes 4, 761-764. 
662

663

664

665

666

667

668

669

670

671

672

673

674

675

676

677

678

679

680

681

682

683

684

685

686

687

688

689

690

691

692

693

694

695

696

697

698

699

700

Roques S, Adrados B, Chavez C, et al. (2011) Identification of neotropical felid faeces using RCP-PCR. Molecular Ecology Resources 11, 171-175.

Roques S, Furtado M, Jácomo ATA, et al. (2014) Monitoring jaguar populations (Panthera onca) with non-invasive genetics: a pilot study in Brazilian ecosystems. Oryx doi:10.1017/S0030605312001640

Rosas-Rosas OC, Bender LC (2012) Population status of jaguars (Panthera onca) and pumas (Puma concolor) in northeastern Sonora, Mexico. Acta Zoológica Mexicana (n. s.) 28, 86-101.

Rousset F (2008) Genepop'007: A complete reimplementation of the Genepop software for Windows and Linux. Molecular Ecology Resources 8, 103-106.

Rylands AB, Brandon K (2005) Brazilian protected areas. Conservation Biology 19, 612-618.

Saccheri I, Kuussaari M, Kankare M, et al. (1998) Inbreeding and extinction in a butterfly metapopulation. Nature 392, 491-494.

Sambrook J, Fritschi EF, Maniatis T (1989) Molecular cloning: A laboratory manual, Cold Spring Harbor Laboratory Press, New York.

Sanderson EW, Redford KH, Chetkiewicz CLB, et al. (2002) Planning to save a species: the jaguar as a model. Conservation Biology 16, 58-72.

Sharma S, Dutta T, Maldonado JE, Wood TC, Panwar HS, Seidensticker J. 2013 Forest corridors maintain historical gene flow in a tiger metapopulation in the highlands of central India. Proc R Soc B 280: 20131506. http://dx.doi.org/10.1098/rspb.2013.1506

Shivik JA (2006) Tools for the Edge: What's New for Conserving Carnivores. Bioscience 56, 253-259.

Silveira L, Jacomo ATA, Astete S, et al. (2010) Density of the Near Threatened jaguar Panthera onca in the Caatinga of north-eastern Brazil. Oryx 44, 104-109.

Silveira L, Sollmann R, Jacomo ATA, et al. (2014) The potential for large-scale wildlife corridors between protected areas in Brazil using the jaguar as model species. Landscape Ecology,.

Soisalo MK, Cavalcanti SMC (2006) Estimating the density of a jaguar population in the Brazilian Pantanal using camera-traps and capture-recapture sampling in combination with GPS radiotelemetry. Biological Conservation 129, 487-496. 
Sollmann R, Mundim Tôrres N, Silveira L (2008) Jaguar Conservation in Brazil: The Role of

Protected Areas. CAT News Special Issue 4 - The Jaguar in Brazil.

704

705

706

707

708

709

710

711

712

713

714

715

716

717

718

719

720

721

722

723

724

725

726

727

728

729

730

731

732

733

734

735

736

737

738

739
Srikwan S, Woodruff DS (2000) Genetic erosion in isolated small mammal populations following rain forest fragmentation. In: Genetics, Demography and Viability of Fragmented Populations. Young A. and Clarke G (Eds.). Cambridge Univ. Press, Cambridge, pp. 149-172.

Swartz FA (20000 The Pantanal in the 21st century - for the planet's largest wetland, an uncertain future. In: The Pantanal of Brazil, Paraguay and Bolivia. Swartz F A (Ed.). Hudson MacArthur Publishers, Gouldsboro, Pennsylvania, pp. 1-24.

Taberlet P, Waits LP, Luikart G (1999) Noninvasive genetic sampling: look before you leap. Trends in Ecology and Evolution 14, 321-325.

Tallmon DA, Koyuk A, Luikart G, Beaumont MA (2008) ONeSAMP: A program to estimate effective population size using approximate Bayesian computation. Molecular Ecology Resources 8, 299301.

Thompson WL (2004) Sampling rare or elusive species: Concepts, designs, and techniques for estimating population parameters. Island Press, Washington, D.C., USA.

Vucetich JA, Waite TA (2003) Spatial patterns of demography and genetic processes across

the species' range: null hypotheses for landscape conservation genetics. Conservation Genetics 4, 639645.

Vynne C, Keim JL, Machado RB, et al. (2011a) Resource Selection and Its Implications for Wide-Ranging Mammals of the Brazilian Cerrado. Plos One 6.

Vynne C, Skalski JR, Machado RB, et al. (2011b) Effectiveness of Scat-Detection Dogs in Determining Species Presence in a Tropical Savanna Landscape. Conservation Biology 25, 154-162.

Waples RS, Do C (2008) LDNE: A program for estimating effective population size from data on linkage disequilibrium. Molecular Ecology Resources 8, 753-756.

Weir BS, Cockerham CC (1984) Estimating F-Statistics for the Analysis of Population-Structure. Evolution 38, 1358-1370.

Williams BK, Nichols JD, Conroy MJ (2002) Analysis and management of animal populations. Academic 
741

742 Zeller K (2007) Jaguars in the new millennium data base update: the state of the jaguar in 743 2006. Wildlife Conservation Society-Jaguar Conservation Program, New York, USA.

744

745 
Figure 1. A. Map of the actual jaguar's geographic range (Panthera onca), sampling sites (black points), genetic clusters and principal ecosystems in Brazil and Mexico (see details and codes in Table 1). The map is based on information from the IUCN Red List of Threatened Species (IUCN 2013). B. Map of the potential corridors connecting protected jaguar populations in Brazil and degree of disturbance from Silveira et al. (2014)

Figure 2. Isolation by distance across jaguar populations. Pairwise genetic differentiation as FST/(1-FST) at (A) Multi-regional scale including Mexico ( $n=15$ populations) and (B) Regional scale; Brazil ( $n=9$ populations). In grey, genetic comparisons involving CAPV, the easternmost Brazilian sampling site.

Figure 3. A. The genetic structure of the Brazilian populations identified by the STRUCTURE analysis assuming four genetic clusters ( $K=4$; MEXC, AMAZ, PANT and CAPV) in the overall population. Individuals are represented as bars partitioned into segments corresponding to their membership in genetic clusters indicated by the colors. Individuals from the Central areas (CENT: ARAG, PNEM, CANT) show from $50 \%$ to $100 \%$ ancestry in AMAZ, and the remainder corresponding to the other two clusters B. Three-dimensional Factorial Component Analysis graph. Names are referred to sampling sites (see Table 1). Jaguars from the central Brazilian areas (CENT) are intermediate between three differentiated groups (PANT, CAPV and AMZN). MEXC are genetically highly differentiated from the remaining samples. 
Figure 1.
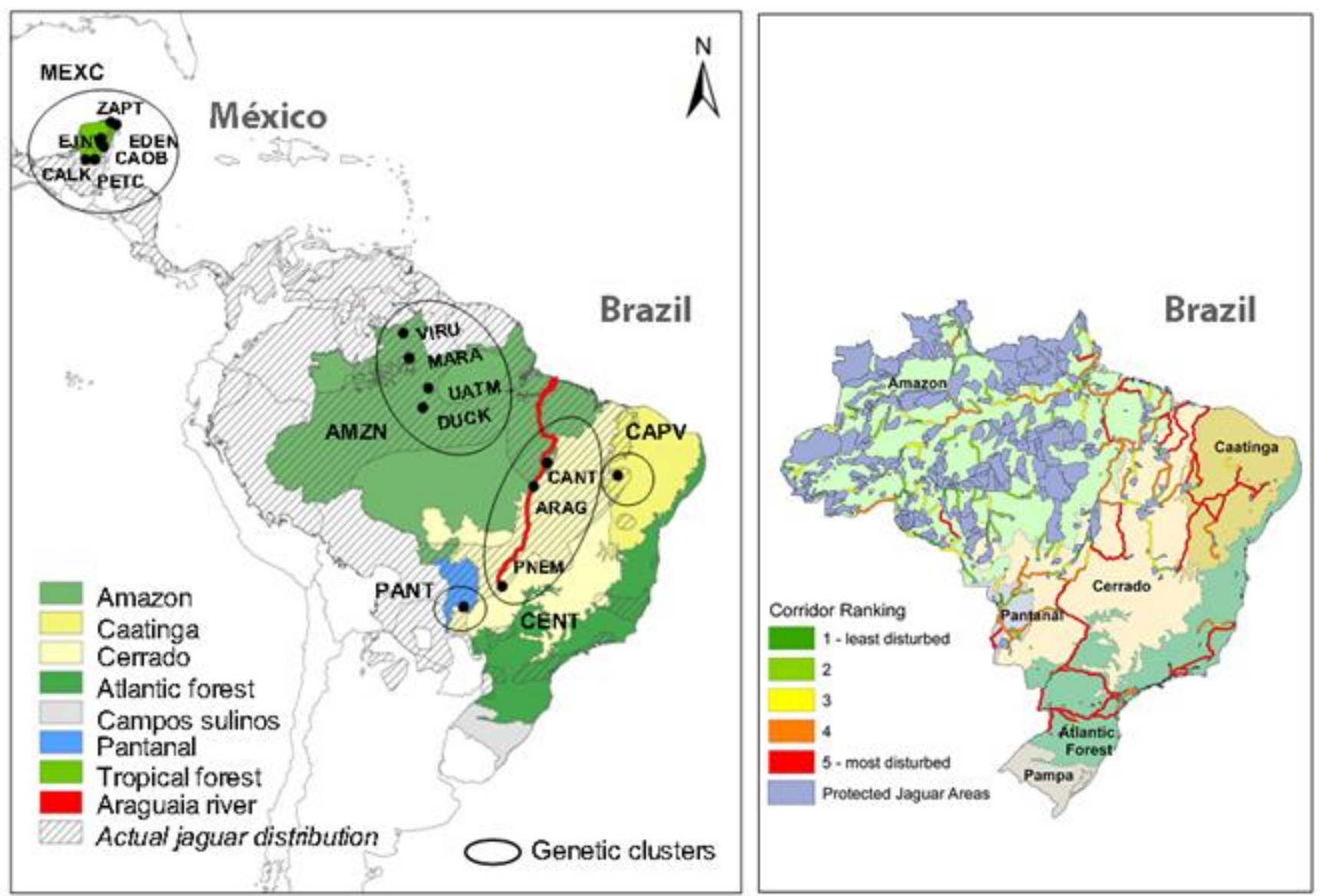

A.

B. 
Figure 2.

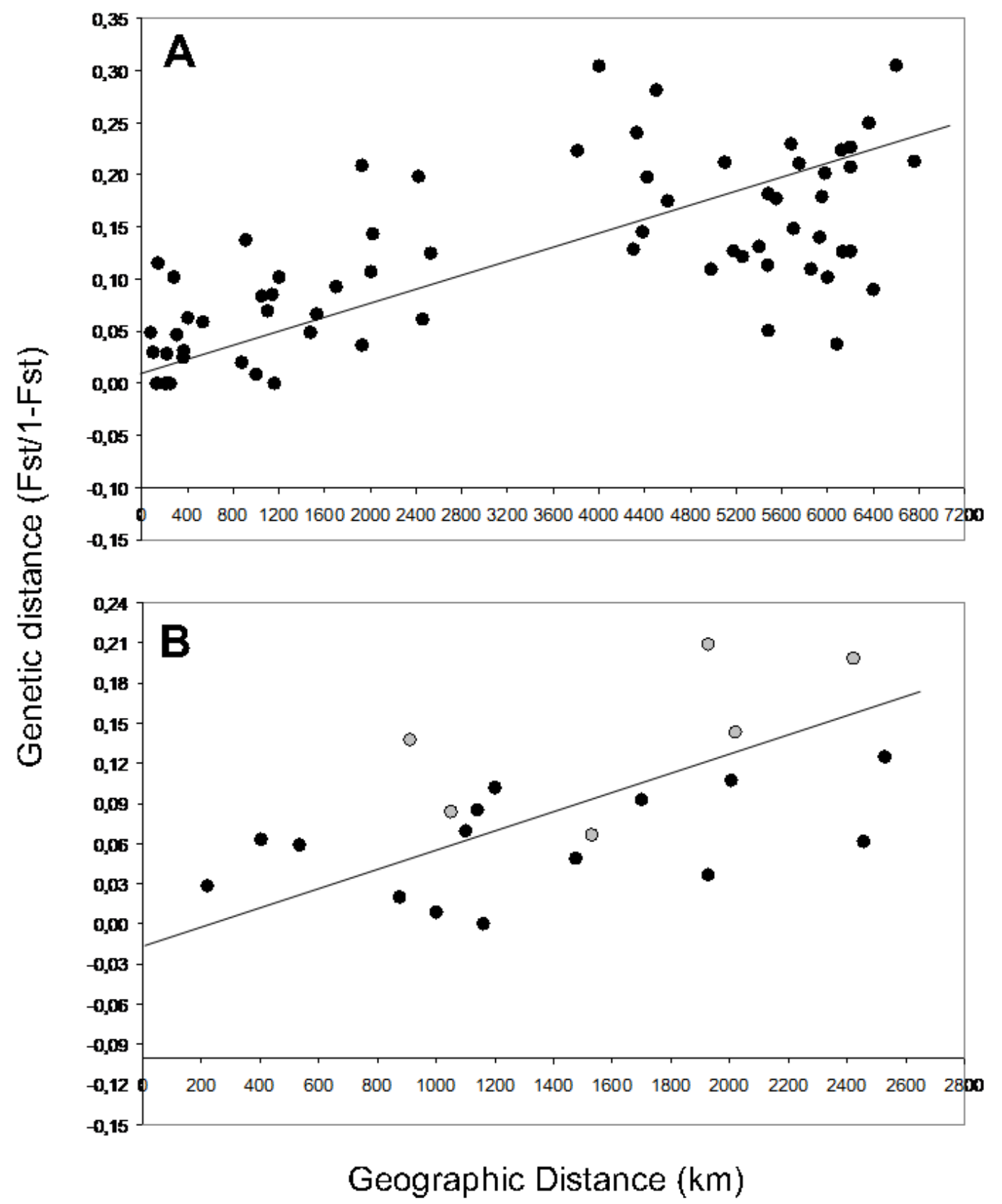


Figure 3.

A.
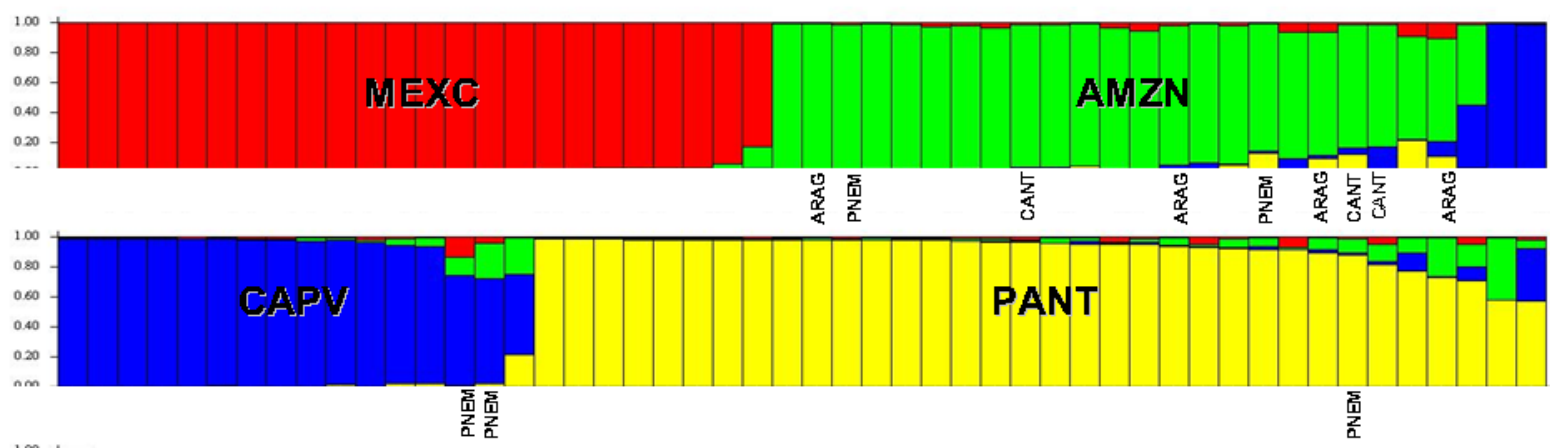

B.

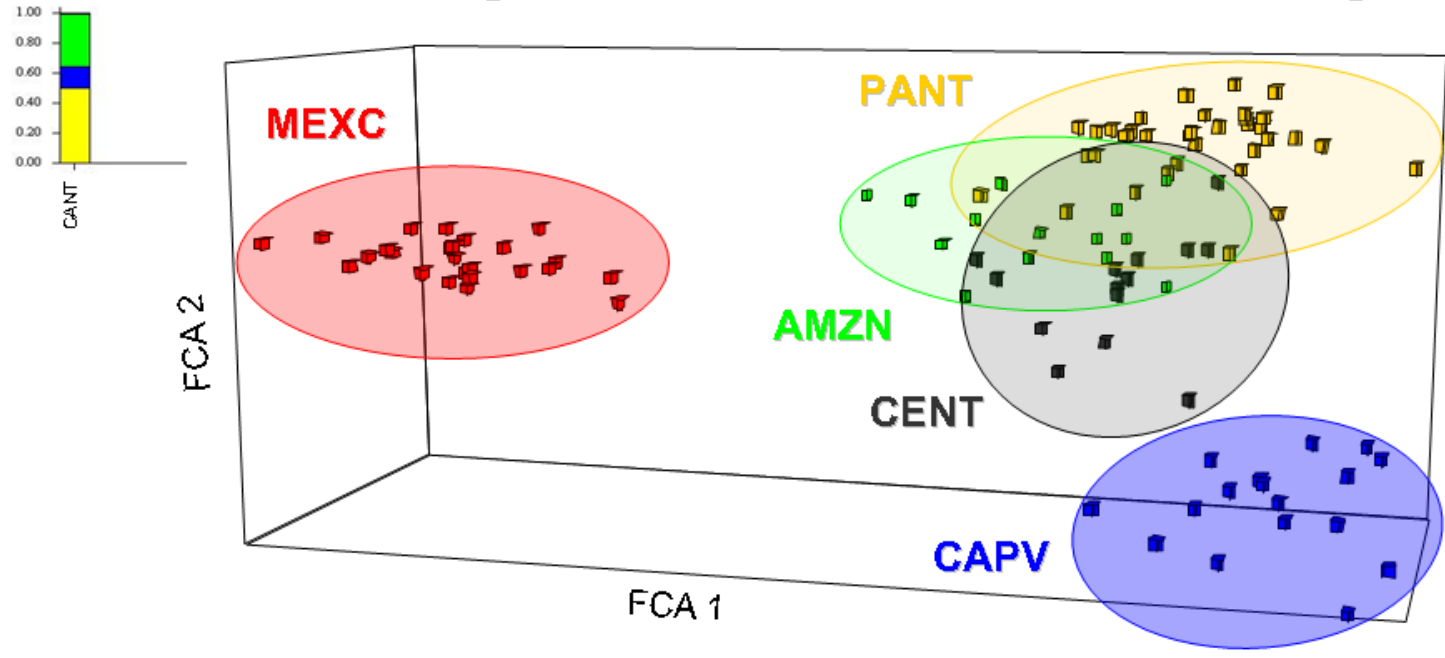




\begin{tabular}{|c|c|c|c|c|c|c|c|c|c|c|}
\hline \multirow{2}{*}{$\begin{array}{c}\text { Biome } \\
\text { AMAZON }\end{array}$} & \multirow{2}{*}{$\begin{array}{c}\text { Code Biome } \\
\text { AMZN }\end{array}$} & \multirow[t]{2}{*}{ Sampling areas } & \multirow[t]{2}{*}{ Code area } & \multirow[t]{2}{*}{$\mathbf{N}$ faeces } & \multirow[t]{2}{*}{$\mathrm{N}$ other } & \multirow[t]{2}{*}{ N Species ID } & \multirow[t]{2}{*}{$\mathrm{N}$ jaguar } & \multirow{2}{*}{$\frac{\mathrm{N} \text { ind }}{12}$} & \multicolumn{2}{|c|}{ Coordinates } \\
\hline & & & & & & & & & & \\
\hline & & Adolfo Ducke Reserve & DUCK & 104 & 0 & 56 & 21 & 6 & $02^{\circ} 55^{\prime} \mathrm{S}$ & $59^{\circ} 59^{\prime} \mathrm{W}$ \\
\hline & & Uatumã Biological Reserve & UATM & 29 & 0 & 19 & 6 & 3 & $1^{\circ} 46^{\prime} \mathrm{S}$ & $-59916^{\prime} \mathrm{W}$ \\
\hline & & Maracá Ecological Station & MARA & 19 & 0 & 13 & 2 & 1 & $3^{\circ} 24^{\prime} 26^{\prime \prime} \mathrm{N}$ & $61^{\circ} 29^{\prime} 13^{\prime \prime} \mathrm{W}$ \\
\hline & & Viruá National Park & VIRU & 46 & 0 & 33 & 8 & 2 & $1029^{\prime} 9^{\prime \prime} \mathrm{N}$ & $61^{\circ} 2^{\prime} 10^{\prime \prime} \mathrm{W}$ \\
\hline CAATINGA & CAPV & Capivara National Park & CAPV & 82 & 0 & 57 & 53 & 18 & $8026^{\prime} \mathrm{S}$ & $42019^{\prime} \mathrm{W}$ \\
\hline \multirow[t]{6}{*}{ CERRADO } & CENT & & & & & & & 14 & & \\
\hline & & Araguaia & ARAG & na & 1 skin & na & na & 1 & $325^{\prime} 13^{\prime \prime}$ & $5326^{\prime} 26^{\prime \prime}$ \\
\hline & & & ARAG & na & 11 liver & na & na & 3 & to $1815^{\prime} 40^{\prime \prime} \mathrm{S}$ & to $4753^{\prime} 07^{\prime \prime} \mathrm{W}$ \\
\hline & & Parque Estadual do Cantão & CANT & na & 4 blood & na & na & 4 & & \\
\hline & & Das Emas National Park & PNEM & 61 & 0 & 49 & 14 & 3 & $18^{\circ} 19^{\prime} \mathrm{S}$ & $52^{\circ}-45^{\prime} \mathrm{W}$ \\
\hline & & & PNEM & & 3 blood & na & na & 3 & & \\
\hline \multirow[t]{2}{*}{ PANTANAL } & PANT & Refúgio Ecológico Caiman & PANT & 98 & 0 & 79 & 37 & 34 & $19^{\circ} 57^{\prime} \mathrm{S}$ & $56^{\circ} 18^{\prime} \mathrm{W}$ \\
\hline & & & PANT & na & 22 blood & na & na & 22 & & \\
\hline \multirow[t]{9}{*}{ MEXICO } & MEXC & & & & & & & 24 & Latitudes & Longitudes \\
\hline & & Ecological reserve El Zapotal & ZAPT & 68 & 0 & 60 & 40 & 5 & $21^{\circ} 20^{\prime} 25^{\prime \prime} \mathrm{N}$ & $87^{\circ} 36^{\prime} 20^{\prime \prime} \mathrm{W}$ \\
\hline & & Ecological reserve El Eden & EDEN & 64 & 0 & 44 & 25 & 3 & $21^{\circ} 13^{\prime} \mathrm{N}$ & $87^{\circ} 11 \mathrm{~W}$ \\
\hline & & Ejido20Noviembre & EJNV & 4 & 0 & 3 & 0 & 0 & & \\
\hline & & Calakmul & CALK & 18 & 0 & 16 & 5 & 3 & $18^{\circ} 11^{\prime} 05^{\prime \prime} \mathrm{N}$ & $89^{\circ} 44^{\prime} 49^{\prime \prime} \mathrm{W}$ \\
\hline & & Petcacab & PETC & 21 & 0 & 17 & 10 & 4 & $19^{\circ} 17^{\prime} 15^{\prime \prime} \mathrm{N}$ & $88^{\circ}$ 13'32.7” W \\
\hline & & Ejido Caobas & САОВ & 34 & 0 & 27 & 14 & 9 & $18^{\circ} 14^{\prime} \mathrm{N}$ & $89^{\circ} 03^{\prime} \mathrm{W}$ \\
\hline & & & САОВ & na & 6 skin & na & na & 6 & & \\
\hline & & & САОВ & na & 1 blood & na & na & 0 & & \\
\hline TOTAL & & & & 209 & 50 & 167 & 94 & 102 & & \\
\hline
\end{tabular}

Table 1: Sampling sites $(n=14)$ in the different biomes of the jaguar distribution in Mexico and Brazil, number of field collected faeces after DNA extraction ( $\mathrm{N}$ faeces) and other material ( $\mathrm{N}$ other), species identification ( $\mathrm{N}$ species $\mathrm{ID}$ ), number of jaguar faeces ( $\mathrm{N}$ jaguar), number of jaguar individuals ( $\mathrm{N}$ ir in bold, total number of jaguars after the assignment strategy for both faeces and high quality DNA sources, and geographical coordinates. na: not applicable

\begin{tabular}{cccccc}
\hline & MEXC & CAPV & AMZN & PANT & CENTR \\
\hline MEXC & -- & & & & \\
CAPV & 0,190 & -- & & & \\
AMZN & 0,135 & 0,115 & -- & & \\
PANT & 0,162 & 0,168 & 0,087 & -- & \\
CENTR & 0,107 & 0,067 & $0,026^{*}$ & 0,067 & -- \\
\hline
\end{tabular}

Table 2: $\mathrm{F}_{\mathrm{st}}(\mathrm{left})$ indices of genetic differentiation among defined jaguar populations for Mexico (MEXC); Caatinga (CAPV); Amazon (AMZN); Pantanal (PANT); and Central areas (CENTR). All values are highly significant $(P \leq 0.01)$ except * $(P \geq 0.05)$ 


\begin{tabular}{|c|c|c|c|c|c|c|}
\hline \multirow[t]{2}{*}{ Sample name } & \multirow[t]{2}{*}{ Sampling site } & \multicolumn{2}{|c|}{ STRUCTURE Q, K=3 } & \multicolumn{3}{|c|}{ GENECLASS migrant } \\
\hline & & PANT & CAPV & AMZN & 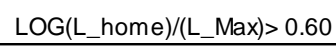 & Origin \\
\hline PANT_SGM11 & PANT & 0.224 & 0.006 & 0.770 & & \\
\hline PANT_SGH27 & PANT & 0.420 & 0.010 & 0.570 & & \\
\hline CANT_1-5 & CENT & 0.013 & 0.036 & 0.950 & & \\
\hline CANT_H2-6 & CENT & 0.100 & 0.047 & 0.853 & & \\
\hline CANT_M113 & CENT & 0.007 & 0.202 & 0.791 & & \\
\hline ARAG_M1 & CENT & 0.009 & 0.063 & 0.928 & & \\
\hline ARAG_M2 & CENT & 0.188 & 0.031 & 0.782 & & \\
\hline ARAG_H3 & CENT & 0.012 & 0.009 & 0.979 & 2.346 & $A M Z N^{* * *}$ \\
\hline ARAG_HM4 & CENT & 0.135 & 0.172 & 0.693 & 1.514 & PANT/AMZN *** \\
\hline PNEM_M1 & CENT & 0.012 & 0.013 & 0.974 & 0.975 & $\mathrm{AMZN}^{* * *}$ \\
\hline PNEM_M2 & CENT & 0.110 & 0.010 & 0.880 & & \\
\hline PNEM_HSG18 & CENT & 0.018 & 0.018 & 0.964 & & \\
\hline CANT_H3-28 & CENT & 0.446 & 0.145 & 0.409 & & \\
\hline PNEM_3 & CENT & 0.029 & 0.659 & 0.312 & 0.601 & $\mathrm{CAPV}^{* \star *}$ \\
\hline PNEM_HSG29 & CENT & 0.028 & 0.681 & 0.291 & 1.984 & $\mathrm{CAPV}^{* * *}$ \\
\hline PNEM SG15 & CENT & 0.830 & 0.013 & 0.158 & 3.230 & PANT ${ }^{* * *}$ \\
\hline DUCK_M2 & AMZN & 0.018 & 0.079 & 0.903 & 1.342 & CENT \\
\hline
\end{tabular}

Jaguars marked with ${ }^{* * *}$ were identified as migrants with both methods.

Table 3: Identification of migrants performed with STRUCTURE and GENECLASS

\begin{tabular}{|c|c|c|c|c|c|c|}
\hline Genetic indices & Parameters/Methods & MEXC & AMZN & PANT & CAPV & CENT \\
\hline & $\mathbf{N}$ & 24 & 12 & 34 & 18 & 14 \\
\hline \multirow[t]{3}{*}{ Diversity } & HE & $0.654+0.147$ & $0.805+0.084$ & $0.726+0.097$ & $0.709+0.133$ & $0.837+0.0490$ \\
\hline & но & $0.684+0.135$ & $0.848+0.099$ & $0.734+0.161$ & $0.779+0.148$ & $0.758+0.1692$ \\
\hline & AR & 5,10 & 6,73 & 5,61 & 5,20 & 7,26 \\
\hline \multirow[t]{2}{*}{ Effective Pop. Size (Ne) } & Onesamp & $30(22-38)$ & 298 (na) & $14(10-17)$ & $14(12-16)$ & na \\
\hline & LDNe & $25(14-45)$ & na (21-inf) & $17(10-28)$ & $13(7-28)$ & na \\
\hline \multirow[t]{5}{*}{ Bottleneck } & Wilcoxon test & & & & & \\
\hline & $P(S M M 5 \%)$ & $0.0005^{\mathrm{S}}$ & $0.0615^{\mathrm{NS}}$ & $0.0508^{\mathrm{NS}}$ & $0.0268^{S}$ & na \\
\hline & $P(S M M 70 \%)$ & $0.0100^{\mathrm{S}}$ & $0.1302^{\mathrm{NS}}$ & $0.4410^{\mathrm{NS}}$ & $0.0500^{\mathrm{S}}$ & na \\
\hline & AF Distribution & $L$-shaped ${ }^{N S}$ & $L$-shaped ${ }^{N S}$ & $L$-shaped ${ }^{N S}$ & $L$-shaped ${ }^{N S}$ & na \\
\hline & M Ratio & $0.888+0.041^{N S}$ & $0.752+0.029^{N S}$ & $0.717+0.041^{N S}$ & $0.670+0.057^{N S}$ & na \\
\hline
\end{tabular}

Table 4: Summary of genetic indices of defined populations for Mexico (MEXC); Caatinga (CAPV); Amazon (AMZN); Pantanal (PANT); and Central areas (CENT). Values are provided for number of jaguars (N), expected (HE) and observed (HO) heterozygosities, and allelic richness (AR), P values are noted as statistically significant $(\mathrm{P} \leq 0.001)\left({ }^{\mathrm{S}}\right)$ and non significant $\left({ }^{\mathrm{NS}}\right)$; na signifies no applicable. Details of the methods are provided in the Material and Methods section. 


\begin{tabular}{|c|c|c|c|c|c|c|}
\hline Study sites * & Geographic scale & $\mathbf{N}^{\mathrm{S}}$ & $\mathbf{N}^{\mathrm{L}}$ & $\mathbf{N}^{\mathrm{A}}$ & HE & References \\
\hline MEXICO & Regional & 24 & 11 & 5,10 & 0,654 & This study \\
\hline $\begin{array}{l}\text { (Yucatan peninsula) } \\
\text { CENTRAL AMERICA } \\
\text { (Mexico, Guatemala, Panama, Costa Rica, Nicaragua) }\end{array}$ & MultiRegional & 16 & 29 & 5,20 & 0,622 & Eizirik et al. 2001 \\
\hline $\begin{array}{l}\text { NORTH -SOUTH AMERICA } \\
\text { (Mexico-CA-Venezuela, French Guyana) }\end{array}$ & MultiRegional & 25 & 29 & 6,80 & 0,695 & Eizirik et al. 2001 \\
\hline GUATEMALA-PARAGUAY & MultiRegional & 107 & 12 & 11,00 & 0,846 & Ruiz-Garcia 2007 \\
\hline COLOMBIA & Regional & 62 & 12 & 10,00 & 0,835 & Ruiz-Garcia 2006 \\
\hline PERU & Regional & na & 12 & 7,00 & 0,860 & Ruiz-Garcia 2007 \\
\hline BOLIVIA & Regional & na & 12 & 7,00 & 0,860 & Ruiz-Garcia 2007 \\
\hline BRAZIL & & 59 & 11 & & & \\
\hline Amazon & Regional & 18 & 11 & 6,90 & 0,805 & This study \\
\hline Cerrado & Regional & 12 & 11 & 7,45 & 0,802 & This study \\
\hline Pantanal & Regional & 34 & 11 & 7,00 & 0,726 & This study \\
\hline Caatinga & Regional & 17 & 11 & 5,55 & 0,709 & This study \\
\hline $\begin{array}{l}\text { NORTH ARGENTINA/SOUTH BRAZIL } \\
\text { Atlantic Forest (Upper Parana) }\end{array}$ & Regional & 13 & 13 & 6,00 & 0,737 & Haag et al. 2010 \\
\hline $\begin{array}{l}\text { SOUTH -SOUTH AMERICA } \\
\text { (Brazil, Bolivia , Paraguay) }\end{array}$ & MultiRegional & 17 & 29 & 6,70 & 0,724 & Eizirik et al. 2001 \\
\hline \multirow[t]{2}{*}{ MEXICO-BRAZIL } & Distribution range & 42 & 29 & 8,30 & 0,739 & Eizirik et al. 2001 \\
\hline & Distribution range & 102 & 11 & 10,55 & 0,800 & This study \\
\hline
\end{tabular}

Table 5: Genetic surveys based on microsatellites markers that estimate the diversity of jaguar populations at different geographic scales. Study sites are ordened from north to south of the jaguar distribution range (See also Figure 1). Number of samples $\left(\mathrm{N}^{\mathrm{S}}\right)$, loci $\left(\mathrm{N}^{\mathrm{L}}\right)$, alleles $\left(\mathrm{N}^{A}\right)$, and expected (HE) heterozygosity. na indicates not applicable. See Supplementary Material for additional information on studied areas (codes, biomes, country, distances between sites, etc.). 
S1. Fst values (below left) and Geographic distances (above right, in kms) between jaguar sampling sites. Significant values are indicated in bold (P $\leq 0.01$ ); na signifies not applicable (for sampling sites with $\mathrm{n}<3$ individuals)

\begin{tabular}{|c|c|c|c|c|c|c|c|c|c|c|c|c|c|c|}
\hline & CALK & САОВ & PETC & EDEN & ZAPT & CAPV & DUCK & UATM & VIRU & MARA & CANT & PANT & PNEM & ARAG \\
\hline CALK & & 98 & 142 & 362 & 281 & 6360 & 4600 & 4452 & 4000 & 4222 & 5475 & 5680 & 6130 & 5700 \\
\hline САОВ & 0,0291 & & 78 & 366 & 306 & 6120 & 4300 & 4152 & 3810 & 4032 & 5175 & 5480 & 5930 & 5400 \\
\hline PETC & 0,1034 & 0,0467 & & 248 & 208 & 6200 & 4380 & 4232 & 4420 & 4642 & 5255 & 5550 & 6000 & 5480 \\
\hline EDEN & 0,0244 & 0,0304 & $-0,0397$ & & 130 & 6760 & 4980 & 4832 & 4330 & 4552 & 5855 & 5950 & 6400 & 6080 \\
\hline ZAPT & 0,0926 & 0,0447 & $-0,0215$ & $-0,0166$ & & 6600 & 5100 & 4952 & 4500 & 4774 & 5975 & 5750 & 6200 & 6200 \\
\hline CAPV & 0,2000 & 0,1830 & 0,1847 & 0,1756 & 0,2339 & & 1995 & 2143 & 2380 & 2158 & 1050 & 2100 & 2139 & 910 \\
\hline DUCK & 0,1490 & 0,1140 & 0,1269 & 0,0988 & 0,1750 & 0,1255 & & 148 & 600 & 378 & 875 & 1500 & 1950 & 1100 \\
\hline UATM & 0,1472 & 0,1381 & 0,1371 & 0,1130 & 0,1895 & 0,0961 & 0,0200 & & 370 & 230 & 1023 & 1648 & 2098 & 1248 \\
\hline VIRU & na & na & na & na & na & na & na & na & & 222 & 1475 & 2170 & 2630 & 1700 \\
\hline MARA & na & na & na & na & na & na & na & na & na & & 1253 & 1948 & 2408 & 1480 \\
\hline CANT & 0,1018 & 0,1127 & 0,1085 & 0,0989 & 0,1679 & 0,0774 & 0,0197 & $-0,0342$ & na & na & & 1140 & 1160 & 220 \\
\hline PANT & 0,1869 & 0,1541 & 0,1506 & 0,1519 & 0,1743 & 0,1729 & 0,0969 & 0,0547 & na & na & 0,0785 & & 478 & 1200 \\
\hline PNEM & 0,1123 & 0,1230 & 0,0923 & 0,0826 & 0,1720 & 0,0625 & 0,0354 & $-0,0046$ & na & na & $-0,0261$ & 0,0594 & & 1000 \\
\hline ARAG & 0,1294 & 0,1161 & 0,0483 & 0,0364 & 0,1125 & 0,1209 & 0,0650 & $-0,0244$ & na & na & 0,0276 & 0,0925 & 0,0087 & \\
\hline
\end{tabular}

S2. Sampling sites identification

\begin{tabular}{lccl}
\hline Codes & Country & Biome & Sampling area \\
\hline DUCK & Brazil & AMAZON & Adolfo Ducke Reserve \\
UATM & Brazil & AMAZON & Uatumã Biological Reserve \\
MARA & Brazil & AMAZON & Maracá Ecological Station \\
VIRU & Brazil & AMAZON & Viruá National Park \\
CAPV & Brazil & CAATINGA & Capivara National Park \\
ARAG & Brazil & CENTRAL & Araguaia \\
PNEM & Brazil & CENTRAL & Das Emas National Park \\
CANT & Brazil & CENTRAL & Parque Estadual do Cantão \\
PANT & Brazil & PANTANAL & Refúgio Ecológico Caiman \\
ZAPT & Mexico & YUCATAN & Ecological reserve El Zapotal \\
EDEN & Mexico & YUCATAN & Ecological reserve El Eden \\
EJNV & Mexico & YUCATAN & Ejido 20 Noviembre \\
CALK & Mexico & YUCATAN & Calakmul \\
PETC & Mexico & YUCATAN & Petcacab \\
CAOB & Mexico & YUCATAN & Ejido Caobas \\
\hline
\end{tabular}

S4. Evanno Table output for all $\mathrm{K}$ values

\begin{tabular}{ccccccc}
\hline $\mathrm{K}$ & Reps & \multicolumn{1}{c}{ Mean LnP(K) } & $\operatorname{Stdev} \operatorname{LnP}(\mathrm{K})$ & $\operatorname{Ln}^{\prime}(\mathrm{K})$ & $\left|\operatorname{Ln}^{\prime \prime}(\mathrm{K})\right|$ & Delta K \\
\hline 1 & 20 & -4137.635000 & 0.702083 & - & - & - \\
2 & 20 & -3833.175000 & 14.642256 & 304.460000 & 76.350000 & 5.214360 \\
3 & 20 & -3605.065000 & 1.781270 & 228.110000 & 125.100000 & 70.230810 \\
4 & 20 & -3502.055000 & 2.305251 & 103.010000 & 286.510000 & 124.285791 \\
5 & 20 & -3685.555000 & 175.872189 & -183.500000 & 263.440000 & 1.497906 \\
6 & 20 & -3605.615000 & 114.975390 & 79.940000 & - & - \\
\hline
\end{tabular}


Supplementary file S3 : Database of 102 jaguars for 11 microsatellites in 14 sampling sites in Mexico and Brazil

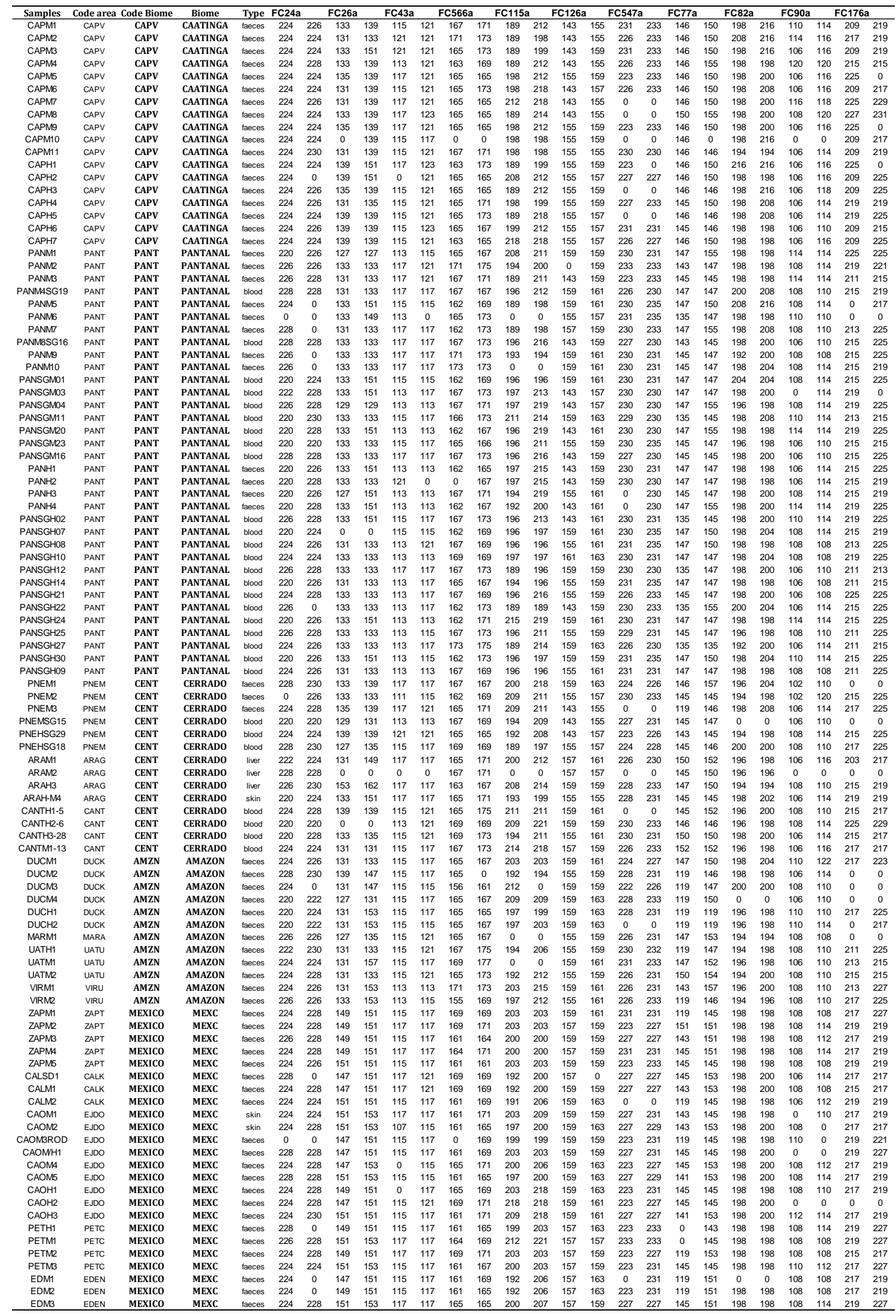

